\title{
A INTENCIONALIDADE PARA A APRENDIZAGEM SIGNIFICATIVA DA BIOMECÂNICA: REFLEXÕES SOBRE POSSÍVEIS EVIDÊNCIAS EM UM CONTEXTO DE FORMAÇÃO INICIAL DE PROFESSORES DE EDUCAÇÃO FÍSICA
}

\author{
Intentionality in biomechanics meanginful learning: \\ considerations about possible evidences in a context \\ of initial education for Physical education teachers
}

Rachel Saraiva Belmont ${ }^{1}$. Evelyse dos Santos Lemos ${ }^{2}$

\begin{abstract}
Resumo: Assumindo a Biomecânica como um conhecimento essencial para a prática do professor de Educação Física, a presente investigação, qualitativa e do tipo estudo de caso, buscou evidências sobre a intencionalidade do aluno para aprender. Ou seja, pretendeu identificar se o tipo de interação que os alunos estabelecem entre si, com o professor e com o conhecimento/ disciplina favoreceu a aprendizagem significativa pelos mesmos. Tomando por base a Teoria da Aprendizagem Significativa e utilizando a observação participante como estratégia metodológica, os registros obtidos foram variados e, conforme a natureza, categorizados pela Análise de Conteúdo ou tratados por um teste de correlação estatística. Os resultados apontam o número de falas como indicador impreciso para caracterizar a intencionalidade para aprender. No entanto, a atenção à natureza das interações, assim como aos hábitos de estudo, apresentaram-se como indicadores apropriados para a questão. No presente caso, a maioria dos 13 alunos apresentou intencionalidade para a aprendizagem mecânica.
\end{abstract}

Palavras-chave: Biomecânica. Aprendizagem significativa. Análise de conteúdo. Educação física.

\begin{abstract}
Assuming Biomechanics as essential knowledge for Physical Education teacher practice, the present work searched for evidence of student intentionality to learn. By means of qualitative and case study research, we intended to verify if the students' way of interaction with each other, with the teacher and the subject's main theme improved meaningful learning. Meaningful Learning Theory was our theoretical framework and participant observation our methodological strategy. The records were varied and classified according to their nature by Content Analysis or treated by a correlation test. The results show the number of speech interactions is an imprecise indicator to define intentional learning, whereas attention to the nature of interaction as well as to study habits can be presented as appropriate ones. In this specific case, most of the thirteen students showed intentionality to rote learning.

Keywords: Biomechanics. Meaningful learning. Physical education. Content analysis.

${ }^{1}$ Pós-Graduanda Stricto Sensu em Ensino em Biociências e Saúde, Instituto Oswaldo Cruz, Fundação Oswaldo Cruz (IOC/Fiocruz). Pavilhão Lauro Travassos, sala 23. Av. Brasil, 4365, Manguinhos. Rio de Janeiro, RJ, Brasil. 21.040-360. rachelsbelmont@gmail.com

${ }^{2}$ Programa de Pós-Graduação Stricto Sensu em Ensino em Biociências e Saúde, IOC/Fiocruz. Rio de Janeiro, RJ, Brasil.
\end{abstract}


Belmont, R. S.; Lemos, E. S.

\section{Introdução}

A Biomecânica, comumente definida como "[...] a aplicação dos princípios da Mecânica ao estudo dos problemas biológicos" (ENOKA, 2000, p. 1), é um conhecimento central para a adequada atuação do profissional do campo da Educação Física. Nessa área, caracteriza-se como uma "[...] ciência voltada ao estudo dos comportamentos físico-mecânicos do corpo humano, dentre os quais o movimento corporal, segundo um ponto de vista claramente definido" (BATISTA, 2001a, p. 40).

Apesar dessa relevância, a aprendizagem da Biomecânica, provavelmente pela natureza interdisciplinar desta disciplina, costuma exigir muita dedicação dos estudantes que, em geral, consideram-na difícil. Além disso, não é raro constatar que profissionais de Educação Física pouco recorrem aos conceitos da Biomecânica em sua prática profissional.

Amadio e Serrão (2004) ratificam nossa percepção quando afirmam que, embora o avanço dessa Ciência seja alto, tal crescimento não é acompanhado em igual intensidade na intervenção profissional. Sanders e Sanders (2001), em um contexto internacional, apontam para a dificuldade de utilização do conhecimento obtido, com base em pesquisas nessa área, por professores e técnicos. No mesmo sentido, Batista (2001b), ao analisar 87 anos de produção científica do campo da Biomecânica, concluiu que o acervo produzido apresenta pequeno, quando nenhum, grau de aplicabilidade para o ensino de habilidades motoras esportivas. A aparente distância entre os resultados de investigações nesse campo e a apropriação desses por professores não será aqui discutida, entretanto, nos interessa ressaltar que o problema existe e, mesmo sendo multifatorial, passa - também - pelo ensino e pela aprendizagem do tema.

Essa demanda de os professores perceberem a relevância e aplicabilidade dos conceitos centrais da Biomecânica em suas práticas profissionais, somada à nossa ideia de que a interação intra e interpessoal é fundamental para a aprendizagem, nos motivaram a questionar se o tipo de interação que os alunos, da disciplina Biomecânica de um curso de licenciatura em Educação Física, estabelecem com o conhecimento específico favorece a ocorrência da aprendizagem significativa pelos mesmos.

Orientadas por essa questão, apresentaremos, em um primeiro momento, a Teoria da Aprendizagem Significativa (AUSUBEL; NOVAK; HANESIAN, 1980; AUSUBEL, 2003; NOVAK, 2000; GOWIN, 1981; MOREIRA, 2000), referencial teórico que subsidiou esta investigação. Em seguida, apresentaremos o delineamento metodológico, nossos principais resultados e discussões. Nas considerações finais, refletindo sobre a relação entre os resultados e o delineamento metodológico proposto para a análise da intencionalidade para aprender - aspecto subjetivo, mas de suma importância para o sucesso do processo educativo -, esperamos colaborar para o aumento: do conhecimento sobre o processo de ensino e da aprendizagem da Biomecânica, da formação do profissional de Educação Física e, sobretudo, da investigação sobre o ensino em geral, e das condições para a ocorrência da aprendizagem significativa em particular. 
A intencionalidade para a aprendizagem significativa ...

\section{Marco teórico}

A ideia central da Teoria de Ausubel, Novak e Hanesian (1980) é a aprendizagem significativa, conceito que explica a aprendizagem como um processo no qual o indivíduo associa, de forma não arbitrária e substantiva (não literal), novas informações às ideias relevantes já existentes em sua estrutura cognitiva. É essencialmente um processo de assimilação de novos conhecimentos, no qual tanto a nova informação como a estrutura prreexistente acabam modificadas. $\mathrm{Na}$ aprendizagem mecânica - por memorização literal -, a nova informação se relaciona com a estrutura cognitiva do aprendiz de forma arbitrária e literal (pouco ou não relacionada a conhecimentos prévios específicos - subsunçores), resultando em pequena ou nenhuma aquisição de novos significados.

Ausubel (2003) , ao caracterizar esses dois tipos de aprendizagem, nos alertou para a fragilidade do conhecimento aprendido de forma memorística, pois sua utilização está limitada a situações muito similares à aprendida. Por outro lado, o autor explicitou que a possibilidade de resolver situações novas demanda um conhecimento organizado, consolidado, passível de "ancorar" novos significados, aspectos inerentes à aprendizagem significativa. Os dois tipos de aprendizagem, contudo, não são antagônicos e a aprendizagem mecânica é, muitas vezes, desejável, especialmente quando se é apresentado a um novo campo de conhecimento. Pertencentes a um mesmo continuum, a aprendizagem mecânica, necessária quando o indivíduo não dispuser de conhecimentos prévios - subsunçores - em sua estrutura cognitiva, acaba sendo uma etapa prévia à aprendizagem significativa. Neste continuum, a evolução do conhecimento do aprendiz implica maior aproximação - conforme as relações substantivas e não arbitrárias entre as ideias já aprendidas e entre estas e novas - da extremidade da aprendizagem significativa (MOREIRA, 1999), ainda que o limite, inexistente, seja inalcançável. Ou seja, o problema, no processo educativo, não é memorizar informações, mas ficar neste patamar de aprendizagem, sem ajudar o aluno a relacionar as informações aprendidas de forma fragmentada.

Desse modo, a aprendizagem significativa, conforme enfatiza Ausubel (2003), pode e deve ser favorecida pelo professor. Tal aprendizagem, entretanto, somente ocorre se duas condições forem simultaneamente atendidas: o material de ensino deve ser potencialmente significativo e o aprendiz deve apresentar disposição para aprender de forma significativa. Isto é, além do material ter potencial para favorecer o estabelecimento de relações entre os novos significados e os conhecidos pelo aluno, deve existir intencionalidade deste para relacionar tais informações de forma substantiva e não arbitrária. O produto dessa interação é uma nova informação (conceito e/ou proposição) com significado próprio, pessoal, porém, com aspectos do material de ensino compartilhados com o professor.

A compreensão dos conceitos mencionados nos remete ao significado de evento educativo e aos aspectos contextuais, sociais e afetivos que, juntamente com os cognitivos, integram o processo da aprendizagem e do ensino. O evento educativo, de acordo com Novak (2000), é uma situação específica (aula, curso etc.) na qual aprendiz e professor interagem com o conhecimento - negociando os significados do material educativo com vistas a compartilhálos - em um contexto particular. Essa inter-relação e interação entre os referidos elementos, sempre mediados pela avaliação, quinto elemento, dão, a cada evento educativo, uma singularidade própria, sem possibilidade de repetição. 
Gowin (1981), no mesmo sentido, explica o evento educativo como um episódio de ensino no qual o professor, o material educativo e o estudante, estabelecendo uma relação triádica, negociam e compartilham significados. Essa relação, segundo o autor, acontece da seguinte forma: o professor apresenta os significados do material, o aluno capta o significado - pois percebeu e interpretou a informação - e, em seguida, negocia o significado captado apresentando-o ao professor e colegas - com o professor, para que ambos se certifiquem se corresponde ao mesmo significado ensinado, ou seja, se os significados ensinados e captados são correspondentes e, assim, compartilhados. Partindo desse pressuposto, “[...] o ensino é consumado quando o significado do material que o estudante capta é o significado que o professor pretende que esse material tenha para o estudante" (GOWIN, 1981, p. 81). Somente após esse processo, que pode ser breve ou longo, quando o compartilhamento de significados, entre professor, material educativo e o estudante, é alcançado, caberá ao aluno decidir se quer ou não aprender de forma significativa.

São esses aspectos do processo da aprendizagem que, dentre outros, evidenciam que o aluno possui tanta responsabilidade quanto o professor no processo educativo, e nos levaram a refletir sobre a intencionalidade do aluno para aprender. Nosso pressuposto é que a interação pessoal, com o conhecimento, e interpessoal, com os colegas e professores, são fundamentais para a aprendizagem. É por meio delas que o aluno - com intencionalidade para aprender significativamente - pode, após negociar e captar os significados compartilhados, avaliar se os significados "captados" são coerentes com os ensinados e, assim, decidir se lhe interessa aprendê-los ou não.

Não podemos deixar de mencionar que, ensinar e aprender - mesmo com o ensino planejado segundo a Teoria da Aprendizagem Significativa -, não possuem relação direta de causa e efeito. Ou seja, pode não haver aprendizagem significativa com ensino e, contrariamente, ela pode ocorrer independentemente deste. Por vezes, mesmo quando as ações educativas estão voltadas para o favorecimento da aprendizagem significativa e contemplando as condições para sua ocorrência, os estudantes podem apresentar intencionalidade para aprender mecanicamente, e não significativamente, como seria ideal.

Outro pressuposto deste trabalho é que o aprendiz que possui disposição para aprender significativamente e vivencia um ensino potencialmente significativo, escolhe apropriar-se do novo conhecimento de forma não literal e substantiva. Desta forma, ao atribuir um significado pessoal ao novo conhecimento, o aluno adquire maiores condições e autonomia para utilizá-lo em situações e contextos novos e diferentes dos quais o mesmo foi negociado e compartilhado.

Foi nessa perspectiva, sem ignorar que essa não é a única condição para a ocorrência da aprendizagem significativa, que decidimos buscar indicadores sobre a forma com que os alunos interagem com o conhecimento, mais precisamente, refletir sobre a intencionalidade para aprender, significativamente deste grupo de alunos. Nossa expectativa é que os profissionais do contexto educativo - professores e investigadores - dediquem maior atenção à intencionalidade do aluno para aprender (LEMOS, 2006), sobretudo à natureza das falas e interações que estabelecem com o conhecimento nas situações de ensino. 


\section{Metodologia}

Para realizar a presente investigação, de caráter qualitativo e em forma de estudo de caso (LÜDKE; ANDRÉ, 1986), elegemos a disciplina Biomecânica do curso de licenciatura em Educação Física de uma universidade pública do Rio de Janeiro. A disciplina, obrigatória no curso, é oferecida no quarto período ${ }^{3}$, com carga horária total de sessenta horas-aula e ministrada em dois encontros semanais de uma hora e quarenta minutos cada. Essa escolha pautou-se na reconhecida boa qualidade da disciplina, curso e instituição, e, também, na longa experiência do seu professor responsável (cerca de vinte anos), especialmente no fato de ele utilizar, dentre outros referenciais, a Teoria da Aprendizagem Significativa para subsidiar sua prática docente.

O estudo foi realizado com a turma do segundo semestre de 2008, na qual havia 13 alunos matriculados, cinco do sexo feminino e oito do masculino, cujas idades variavam entre 19 e 25 anos. No contexto da disciplina, todas as decisões sobre seu desenvolvimento e condução foram de responsabilidade do professor. A pesquisadora, primeira autora deste artigo, se integrou como professora assistente, embora explicando aos alunos o motivo de sua presença durante as aulas e os objetivos da investigação.

A disciplina, de acordo com o plano de ensino apresentado pelo professor no primeiro dia de aula, tinha como propósito: (1) "[...] capacitar os alunos para a compreensão de conceitos básicos de Biomecânica", e (2) "introduzir os alunos no uso prático ${ }^{4}$ de conceitos e princípios da Biomecânica na elaboração, implementação e controle de estratégias pedagógicas de Educação Física na Escola". O conteúdo programático foi dividido em três blocos e, coerente com o objetivo proposto, não se valorizou, como parece acontecer em outros cursos, a resolução de cálculos matemáticos. O foco da disciplina foi a compreensão e aplicação dos conceitos da Biomecânica em situações práticas, inerentes ao cotidiano do professor de Educação Física.

No Bloco I, o professor indicava um dos capítulos do livro de apoio às discussões, Biomecânica Básica (HALL, 2000), e, nas aulas seguintes, apresentava o tema fomentando a participação dos alunos, ora esclarecendo as dúvidas anunciadas, ora ajudando-os a relacionar as ideias discutidas com suas experiências pessoais. Nos Blocos II e III, excepcionalmente desenvolvidos em conjunto nesse semestre letivo ${ }^{5}$, as aulas iniciavam com uma exposição do tema pelo professor, que era seguida por uma problematização, cuja resolução era discutida em conjunto com os alunos ou proposta por eles. Além disso, sempre comprometido com a facilitação da aprendizagem dos alunos, o professor, desde o início da disciplina, se colocou à disposição para esclarecer dúvidas fora dos horários de aula, indicar e discutir tarefas extraclasse.

\footnotetext{
${ }^{3}$ A duração dos cursos de licenciatura, de acordo com o Parecer CNE/CP 28/2001 (BRASIL, 2001), é de, no mínimo, três anos. O curso de licenciatura em Educação Física dessa instituição tem a duração de três anos e meio (sete períodos).

${ }^{4} \mathrm{O}$ professor da disciplina, neste caso, se referia à utilização dos conceitos e princípios da Biomecânica para subsidiar a prática profissional dos futuros professores.

${ }^{5}$ Esse período letivo contou com uma greve que interrompeu as atividades da Universidade por dois meses, assim, a disciplina foi realizada em trinta encontros.
} 
A coleta de dados se deu, fundamentalmente, por meio de observação participante, de um questionário sobre o perfil dos alunos e de uma entrevista semiestruturada, realizada com os alunos e com o professor. Dessa forma, tomamos como registros nossas notas de campo, as transcrições das gravações em áudio das aulas e das entrevistas, e as respostas ao questionário.

Os registros, conforme a natureza dos mesmos, foram transformados em categorias, por meio da Análise de Conteúdo, a partir da semântica das respostas e considerando suas frequências (BARDIN, 2009), e, então, como dados, subsidiaram a análise de um dos aspectos que influenciam o processo da aprendizagem significativa: a intencionalidade para aprender significativamente dos alunos. Apesar do caráter qualitativo deste estudo, alguns de nossos registros foram quantificados e, assim, triangulados, visando à verificação da existência de correlação estatística entre o número de manifestações verbais dos alunos e as suas correspondentes médias finais, obtidas na conclusão da disciplina. Para esse fim, calculamos o coeficiente de correlação de Pearson utilizando o programa estatístico GraphPad Prism version 5.00 for Windows (2007).

Cientes de que investigar a intencionalidade dos alunos para aprender não é tarefa fácil e que, por não ser um aspecto tradicionalmente investigado, ainda é necessário construir uma metodologia adequada para este fim, optamos pela análise das ações dos alunos, aqui assumidas como possíveis evidências de intencionalidade para aprender significativamente, como: (a) a participação nas aulas, ou seja, o número de falas realizadas para perguntar, responder ou comentar as ideias discutidas durante as aulas; (b) a natureza das interações verbais entre professor e alunos; (c) as situações de interação, refletindo se, de fato, caracterizavam negociação de significados; (d) os hábitos de estudo no Ensino Médio e até o momento da graduação que cursavam; (e) contato com o professor para esclarecer dúvidas em horários extraclasse; (f) pedido de tarefas extras às solicitadas pelo professor; e (g) a avaliação do professor sobre as atitudes dos alunos durante a disciplina levantada com base em entrevista.

A análise que passaremos a apresentar está centrada em 16 encontros, escolhidos aleatoriamente dentre os 23 , dos trinta totais, que não contemplavam trabalhos em grupo, testes e provas. As manifestações verbais dos estudantes consideradas foram as direta ou indiretamente relacionadas ao conteúdo discutido com a participação do professor, exceto exclamações e comentários de outras naturezas. Para garantir o anonimato dos alunos, optamos pela numeração aleatória, de um a 13 , precedida da letra "A" para representar cada "aluno". Todos os sujeitos envolvidos na investigação - alunos, professor e o responsável pelo curso de Educação Física - assinaram um termo de Consentimento Livre e Esclarecido, documento no qual autorizam a utilização dos registros coletados.

\section{Apresentação e discussão dos dados}

Nas aulas referentes ao primeiro Bloco da disciplina, que demandavam leitura prévia dos capítulos e a apresentação de dúvidas, a dificuldade dos alunos para perguntar, responder ou, mesmo, tecer comentários sobre o conteúdo durante aulas era bastante evidente. Com o passar do tempo e o constante incentivo do professor, eles começaram a participar mais, fato que nos permitia identificar, dentre outros aspectos, aqueles que mantinham a leitura dos 
A intencionalidade para a aprendizagem significativa ...

textos em dia. Apesar desse conjunto de aulas ter tomado por base as dúvidas dos alunos, os conceitos que não eram citados por eles, mas considerados relevantes pelo docente, eram por ele mencionados e valorizados.

No decorrer das aulas, conforme os alunos apresentavam suas dúvidas, o professor as organizava e discutia buscando ajudá-los a compreender o tema em questão e, assim, construir uma organização psicologicamente ${ }^{6}$ lógica sobre os tópicos. Em outras situações, conforme a natureza das dúvidas e questões, ele as respondia diretamente ou devolvia a mesma pergunta para outros alunos da classe ou, ainda, devolvia a mesma pergunta reformulada para o mesmo aluno. Todavia, observamos que apesar de elaborarem questões próprias, espontaneamente, a participação dos alunos era, na maior parte das ocasiões, caracterizada por respostas às indagações do professor.

Pela estreita relação entre os vários conceitos discutidos na disciplina, o professor apresentava constante preocupação com a compreensão e aplicação dos mesmos, bem como com as dúvidas ou enganos dos alunos. Desse modo, o ensino foi recursivo, pois quase sempre o docente mencionava ou discutia significados já trabalhados/negociados anteriormente para apresentar outros/novos. Ou seja, os conteúdos já trabalhados eram frequentemente retomados, sempre "apenas para relembrar".

Essa prática, condizente com o referencial teórico aqui assumido, nos parece adequada em um ensino preocupado com a facilitação da aprendizagem significativa. Entretanto, o foco do presente artigo não é analisar se o ensino foi potencialmente significativo, sabidamente uma das duas condições para a ocorrência de aprendizagem significativa. Nosso foco é a intencionalidade do aluno para aprender, significativamente, assumindo que tanto o aluno quanto o professor possuem responsabilidade no processo educativo. A efetiva participação do aluno durante as aulas, esclarecendo dúvidas, questionando e negociando significados do material educativo, com vistas a compartilhá-lo - com o professor e/ou material de ensino e/ ou colegas -, é fundamental para a aprendizagem significativa.

Desse modo, diante do propósito desta investigação e da percepção de que existe uma aceitação, talvez não consciente, especialmente entre professores, de que a mera participação (fala espontânea) é garantia de sucesso do ensino (e, assim, de aprendizagem pelos alunos), nos pareceu importante identificar o número de falas dos alunos durante as aulas e analisar a relação dessas com o aproveitamento dos alunos na disciplina.

De acordo com o Gráfico 1, que apresenta a relação entre o número de manifestações verbais realizadas pelos alunos e as médias finais dos mesmos, obtidas na disciplina, é possível perceber que o rendimento não foi proporcional às manifestações verbais realizadas, com exceção de A13. O aluno A4, embora estivesse cursando a disciplina pela quarta vez e estabelecesse pequena interação com os colegas e professor em sala, conseguiu uma média razoável. Os alunos A2, A9, A10 e A12 foram, respectivamente, os mais participativos, após A13, entretanto, suas médias foram menores que as de A6 e pouco diferiram das de A4, A7, alunos

\footnotetext{
${ }^{6}$ Baseado na proposta de Ausubel, Novak e Hanesian (1980), o conhecimento ensinado tem uma organização lógica que, aprendido pelo sujeito, passará a ser psicológica.
} 
Belmont, R. S.; Lemos, E. S.

pouco participativos segundo o critério "número de falas". A6, pouco participativo, teve o segundo melhor aproveitamento no grupo, fato que, considerando os dados obtidos sobre a formação prévia desse grupo de estudantes, pode estar relacionado com a qualidade dos seus conhecimentos prévios visto que, diferentemente dos demais, parecia ter cursado uma "melhor" escola, neste caso, um curso de Eletrotécnica.

Por outro lado, ainda que nossos dados não nos permitam afirmar tal ideia, nos parece importante relacionar o comportamento (falar/não falar) dos alunos com o significado de "ativo" para a Teoria da Aprendizagem Significativa. Nessa perspectiva, atividade implica ação intencional de pensar com e sobre as ideias em questão, ou seja, atividade é muito mais do que mera fala e/ou movimento e/ou expressões de prazer/curiosidade.

Gráfico 1. Ocorrência de manifestações verbais realizadas pelos alunos, com suas respectivas médias finais, com ou sem o estímulo do professor, contabilizadas em 16 aulas distribuídas ao longo da disciplina.

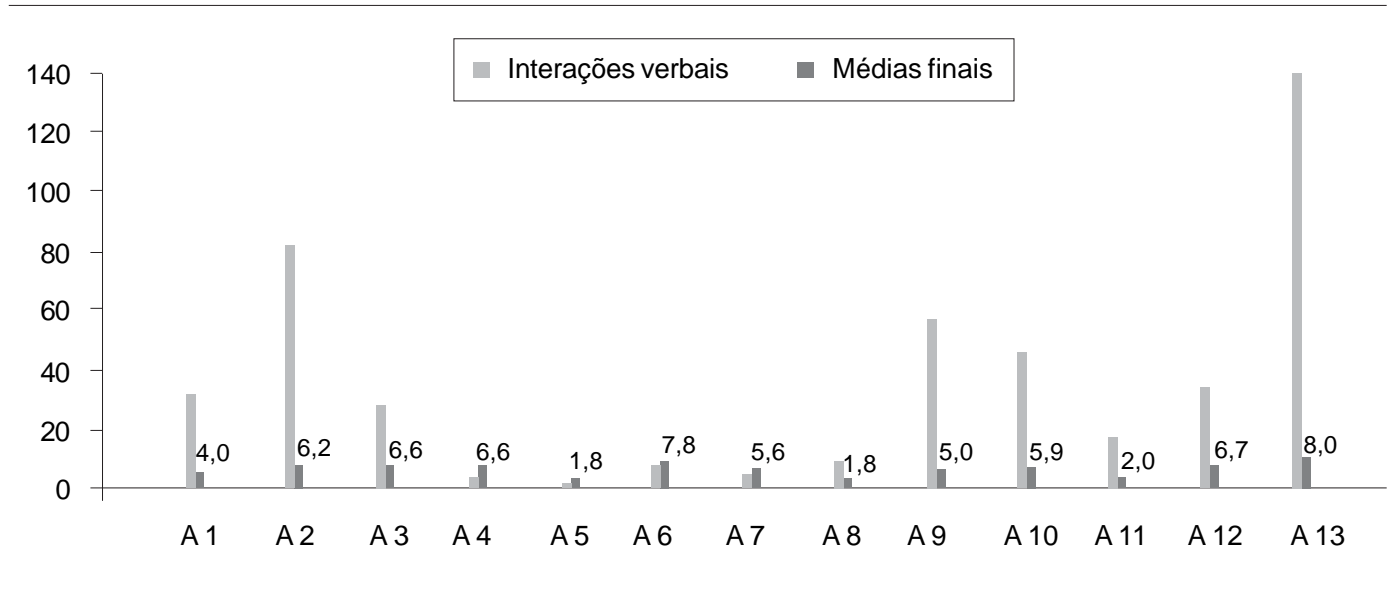

Fonte: Elaborado pelas próprias autoras.

Muito embora a ausência de correspondência entre o número de participações verbais e as médias finais na disciplina nos parecesse clara, decidimos verificar se os dados possuíam distribuição normal. Assim, recorrendo ao cálculo do coeficiente de correlação de Pearson, encontramos uma correlação fraca $(r=0,45)$, ou seja, conforme previsto, as notas finais não estão associadas ou não podem ser explicadas pela quantidade de manifestações verbais.

Tal resultado nos leva a refletir sobre a intenção que estava subjacente às falas dos alunos e ao significado de aprendizagem - mecânica e significativa - explicados por Ausubel, Novak e Hanesian (1980). Isto é, se participação, isoladamente, não reflete o aproveitamento na disciplina, será que suas falas estavam voltadas para a realização de aprendizagem? Em caso afirmativo, será que buscavam aprender mecânica ou significativamente? Em outras palavras, será que a intencionalidade dos alunos estava voltada para a atribuição de significados 
A intencionalidade para a aprendizagem significativa ...

pessoais aos novos conceitos ou, apenas, para o estabelecimento de relações arbitrárias e não substantivas?

Além de reconhecer os diferentes tipos de aprendizagem, a compreensão desses dados demanda atenção ao significado dos conceitos e, sobretudo, ao caráter processual da aprendizagem significativa, além da importância da natureza dos conhecimentos prévios do aprendiz.

Por outro lado, na avaliação dos Blocos II e III da disciplina, cujas questões caracterizavam-se, na sua maioria, como situações novas para os estudantes, as dificuldades foram evidentes mesmo para aqueles que, aparentemente, se esforçavam durante as aulas para captar os significados.

De acordo com nossas observações, alguns dos diálogos evidenciavam falta de atenção à aula ou exemplos pouco relacionados às ideias então discutidas, isto é, foi muito pequeno o número de interações que evidenciaram comprometimento dos alunos com a negociação de significados. Ou seja, embora perguntassem e/ou parecessem prestar atenção faltou, segundo nossa avaliação, uma atitude mais questionadora diante de um novo conhecimento.

Resgatando um dos principais pressupostos da Teoria da Aprendizagem Significativa, a importância do conhecimento prévio para a aprendizagem subsequente, a discrepância entre a participação dos alunos e o aproveitamento na disciplina pode estar relacionada com a natureza do conhecimento prévio dos mesmos. Esse, às vezes sem subsunçores adequados para ancorar as novas informações, às vezes caracterizado como concepção alternativa, às vezes de natureza fragmentada, impõe dificuldades várias ao sucesso do ensino, ou seja, à ocorrência da aprendizagem significativa. No entanto, reiterando não ser o foco deste trabalho, nos interessa destacar o significado de aprendizagem que, mesmo não sendo o objeto da disciplina Biomecânica, caracteriza-se como um conhecimento - prévio - de fundamental importância para o presente estudo e para o ensino em geral.

Estamos assumindo, como um dos indicadores de intencionalidade para a aprendizagem significativa, a interação social, especialmente a relação triádica de Gowin (1981). Nessa perspectiva, o aluno não deve apenas se limitar a responder ao professor. Ele deve responder, perguntar, apresentar suas dúvidas e exemplos, além de (auto) avaliar se os significados captados por ele correspondem aos apresentados pelo professor. Esse tipo de conduta, como antecipado, depende da concepção de aprendizagem que o aluno possui e utiliza para orientar suas ações.

Partindo do exposto, nos debruçamos sobre a natureza dessas interações, ou seja, analisando as 448 verbalizações registradas nos 16 encontros selecionados, identificamos seis categorias de interações, conforme sintetizado no Quadro 1.

O esperado, caso os alunos tivessem uma concepção de aprendizagem coerente com a da Teoria da Aprendizagem Significativa ou, ao menos, com alguma teoria construtivista, seria que os exemplos estivessem similarmente distribuídos nas várias categorias, com alguma tendência de predominância nas categorias 4 e 5 , representantes das interações que expressavam interpretação e negociação das ideias ensinadas. Entretanto, como se depreende do Gráfico 2, que apresenta as categorias e seus respectivos números de interações e os percentuais relativos ao total (448) considerado, houve predomínio (57\%) da Categoria 1, "Resposta direta", a qual agrega as falas dos alunos caracterizadas como resposta às questões postas pelo professor, sem desdobramento do diálogo. 
Belmont, R. S.; Lemos, E. S.

Quadro 1. Categorias correspondentes à natureza das interações verbais dos alunos e suas respectivas considerações

\begin{tabular}{|c|c|c|}
\hline \multicolumn{2}{|r|}{ Categorias } & Considerações \\
\hline 1 & Resposta direta & Responde somente ao que o professor pergunta \\
\hline 2 & Pergunta-dúvida & $\begin{array}{l}\text { Pergunta por que não entendeu os significados discutidos anteriormente ou tem } \\
\text { dúvidas sobre o assunto/tema }\end{array}$ \\
\hline 3 & $\begin{array}{l}\text { Pergunta- } \\
\text { confirmação }\end{array}$ & $\begin{array}{l}\text { Pergunta, normalmente, o que o professor acaba de explicar e/ou discutir com outro } \\
\text { aluno e/ou com ele próprio, a fim de confirmar os significados captados }\end{array}$ \\
\hline 4 & $\begin{array}{l}\text { Pergunta- } \\
\text { aprofundamento }\end{array}$ & $\begin{array}{l}\text { Perguntas sobre outros aspectos do mesmo assunto ou sobre outros exemplos que } \\
\text { envolvam os mesmos conceitos. Também foram incluídas perguntas que } \\
\text { expressavam curiosidades sobre o tem }\end{array}$ \\
\hline 5 & Fala-comentário & $\begin{array}{l}\text { Quando os alunos se expressavam apenas comentando algum aspecto dos } \\
\text { conceitos/assuntos discutidos. Ou seja, não era caracterizado como uma pergunta e } \\
\text { tampouco uma resposta }\end{array}$ \\
\hline 6 & Outros & $\begin{array}{l}\text { Comentários, perguntas ou respostas que não estavam diretamente relacionadas ao } \\
\text { significado dos temas discutidos, como perguntas sobre as provas, referências } \\
\text { bibliográficas ou as próprias impressões sobre os exercícios e outras tarefas }\end{array}$ \\
\hline
\end{tabular}

Fonte: Elaborado pelas próprias autoras.

As demais categorias, corroborando nossas observações, aparecem em menor proporção (42,8\%), muito embora a Categoria 2, denominada "Pergunta-dúvida", apareça em proporção bem maior $(15,8 \%)$ do que as demais. Essa categoria engloba as perguntas levantadas pelos alunos ora porque não haviam captado os significados, ora porque expressavam dúvidas sobre algum aspecto do conteúdo.

As Categorias 3, "Pergunta-confirmação", e 4, "Pergunta-aprofundamento", respectivamente, com questões formuladas visando à confirmação sobre a correspondência entre o significado captado e o apresentado pelo professor), e à tentativa de levar os novos conceitos, discutidos sob uma perspectiva, para outra realidade/contexto, indicam maior preocupação com a compreensão e/ou aprofundamento do texto. Essas Categorias, somadas à 5, "Falacomentário", representam apenas $21,4 \%$ das interações que poderiam culminar em negociações de significados, como ideal, apesar de esta realidade não ter sido constatada, como veremos mais à frente.

Assim, sem desconsiderar que quase $60 \%$ das falas/respostas indicadas na Categoria 1 poderiam refletir negociação pessoal de significado e, também, com o professor, consideramos que este grupo de respostas - em geral pontuais, curtas ou com frases que reproduziam o discurso do professor ou livro-texto - pouco refletiam intencionalidade para aprender. Como será apresentado adiante, independentemente do conteúdo dessas respostas, se houvesse intencionalidade para a aprendizagem significativa, por parte dos alunos, o diálogo não terminaria "nesta" primeira resposta. Esse padrão de resposta, ainda que demande maior aprofundamento acerca da natureza das falas, não parece ser um indicador apropriado para se evidenciar intencionalidade para negociar, compartilhar e, posteriormente à captação dos significados, aprender significativamente o conteúdo. 
A intencionalidade para a aprendizagem significativa ...

Gráfico 2. Categorias da natureza das falas dos alunos com seus respectivos números de manifestações verbais e percentuais relativos ao total de 448 interações.

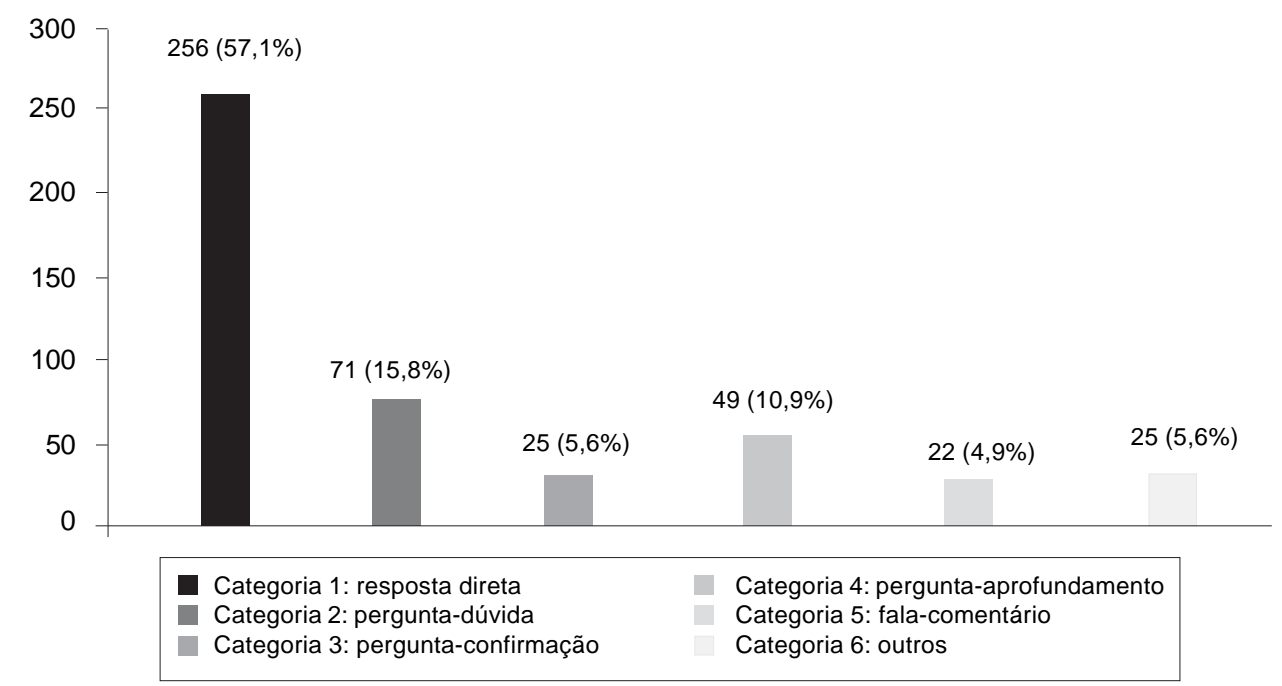

Fonte: Elaborado pelas próprias autoras.

Depreende-se, dessa reflexão, que é preciso analisar a natureza das participações dos alunos para podermos afirmar se caracterizavam, ou não, situações de negociação e compartilhamento dos significados ensinados. Vale lembrar que a negociação de significados pode ocorrer de forma interpessoal (professor - material de ensino - aluno/colegas) ou intrapessoal, quando, ao ouvir os significados, o aluno os interpreta a partir de suas ideias prévias, negociando com suas próprias percepções sobre o fenômeno em questão.

Não obstante, considerando a complexidade da análise das "interações" intrapessoais, nos limitamos a buscar episódios de negociações de significados na perspectiva interpessoal, pois é desta forma que o aluno expõe seus pensamentos. Para esse fim, retomamos as 16 aulas consideradas e, ao analisarmos os diálogos estabelecidos, identificamos poucas situações que poderíamos considerar como exemplos de negociação de significados entre professor, material educativo e alunos na perspectiva de Gowin (1981). Ou seja, apesar do grande número de falas, são raras as interações que se apresentam como diálogos um pouco mais longos e indicando desdobramento do raciocínio, divergências, concordâncias, ou demais possibilidades que caracterizem negociação. Além disso, as conversas raramente constituem-se em trocas entre vários alunos com o professor. Isto é, a prática da negociação de significados, embora evidente em alguns momentos, ainda está longe do que se preconiza como ideal.

Dentre os diálogos identificados, selecionamos dois para exemplificar o que temos dito. O trecho abaixo, extraído da aula 28, retrata a discussão sobre a habilidade motora "lançamento", na qual se deram a captação de significados negociados e compartilhados. Nesse 
Belmont, R. S.; Lemos, E. S.

momento da aula, o professor, considerando as dificuldades expressadas pelos alunos no encontro anterior sobre identificação de movimentos articulares básicos referentes às articulações do cotovelo e ombro, provocou uma discussão que culminou, após explicação deste assunto, no seguinte diálogo:

$[\ldots]$

P: [...] Existem coisas que são básicas. Saber que o cotovelo só faz. flexão e extensão é básico.

A13: [demonstra uma rotação do ombro] Mas se o ombro tiver assim, ele fą...

P: Não importa! O cotovelo só faz flexão e extensão.

A13: [repetindo o movimento anterior] Não, mas isso não é um movimento de rotação?

P: Do ombro. Você só consegue girar porque o ombro gira.

A13: Tá, mas rotação o quê?

P: É só você ver para onde vai o seu segmento.

A1: Medial e lateral.

P: Para fora [rotação] lateral e para dentro, [rotação] medial.

A13, ainda pensativo, mas parecendo convencido, balançou a cabeça positivamente e tomou nota. Nessa passagem, ao manifestar desconhecer que flexão e extensão são as únicas possibilidades de movimentos para a articulação do cotovelo, o aluno em questão atribuiu, equivocadamente, o movimento de rotação a esta articulação, que, na verdade, se efetiva na articulação do ombro. Esse aluno, cujo conjunto de ações na disciplina nos sugere intencionalidade para aprender, não aceitou "literalmente" a afirmativa do professor e exigiu deste argumentos que lhe "convencessem", ou seja, que lhe permitissem perceber a incoerência com a qual percebia e explicava o fenômeno. Com dificuldade para "entender" que o cotovelo não faz movimentos de rotação, conforme explicado pelo professor, A13 interpretou a nova informação usando seus conhecimentos prévios, de natureza equivocada, do tipo "a articulação do cotovelo faz rotação". Desse modo, "vendo e sentindo", via movimento que realizava, que o cotovelo "fazia" rotação, A13 trouxe, para a classe, a ideia de possibilidade de movimentos de rotação para o cotovelo e negociou tal significado com o professor e com os colegas, ainda que somente A1 tenha participado explicitamente da negociação.

Nessa interação, o aluno A13, convencido da sua interpretação, seguiu executando os movimentos de cotovelo e ombro para "demonstrar" o que dizia, e o professor, por sua vez, argumentou contra a sua explicação. Ou seja, este aluno, atuando como desejado, se esforçou para captar os "novos" significados, e, como não concordou com o professor, negociou com o mesmo, ainda que se baseando em uma concepção errônea sobre o movimento articular do cotovelo. O aluno A1, por sua vez, indicando concordar com o professor e discordar de A13, também evidenciou intencionalidade para captar e aprender os significados ensinados, pois negociou com A13. Assumindo que a atitude final de A13 - gesto de concordância, semblante pensativo e anotação no caderno - expressa que ele havia compartilhado o significado ensinado com o professor e A1, nos parece possível afirmar que A13, ao menos nesta situação, apresentava intencionalidade para aprender significativamente. 
A intencionalidade para a aprendizagem significativa ...

Outro exemplo de situação na qual os alunos indicam intencionalidade para aprender significativamente ocorreu na aula 25 , também ocupada com a descrição e análise de movimentos. Os alunos tentavam resolver problemas inerentes à descrição e à análise da habilidade motora "salto vertical" junto com o professor, momento este em que o próprio desenhou graficamente a execução de um "salto vertical" levando em conta as variáveis, força de reação do solo e tempo. Juntos, professor e alunos tentaram relacionar as fases do movimento, descritas momentos antes, a determinados pontos representados no gráfico. Esse foi mais um episódio no qual os alunos se esforçam para negociar e captar os significados que o professor apresentava.

P: Se o sujeito fica parado sobre a plataforma, qual vai ser o registro?

A6: Linear.

P: Sim. Vou ter uma reta ali.

A2: $\mathrm{Na}$ [fase] seis, onde o cara comeşa a saltar?... Lá no gráfico.

P: Onde é?

A2: Quando começa a cair.

P: Aqui é que ele começa a cair... [apontando].

A2: Mais embaixo. Ai é que comeca a cair, não?

P: Perdeu o contato, fase aérea. Aérea positiva, aérea negativa e aqui ele chega ao solo de novo [apontando].

A13: Quando desce, o peso não é três vezes maior? Então quando ele volta está lá em cima, né? [no gráfico].

P: Ele vem do zero e sobe. Você vê aqui [apontando], é maior que o peso corporal...

A13: Não, ai é a [fase] nove. Lá em cima não é a [fase] nove?

P: Aqui embaixo é que é a [fase] nove. Tocou [no solo] e nesse instante aqui, ele faz a reação e continua.

A2: $O$ amortecimento é aonde?

P: $O$ amortecimento é essa curva aqui. O amortecimento vai determinar o tipo de curva...

A1: O ápice, não seria a depressão máxima?

P: Dependendo de como o sujeito faça o amortecimento, a curva dele vai fažendo isso aqui [desenha no gráfico].

A1: Sim, mas o ponto mais alto seria qual etapa?

P: Está um pouco depois disso aqui. Aqui é logo após o contato inicial [apontando].

A9: Esse pico é o quê?

P: Este aqui é na hora em que ele chega aqui [aponta].

A13: Quando você coloca o pé no solo é essa última fase ali, né? [aponta].

P: É isso aqui [aponta].

$[\ldots]$

Nesse diálogo, um dos poucos com a participação de vários alunos, é perceptível a dificuldade de interpretação gráfica do "salto vertical". Os alunos A1, A2 e A13 apresentaram 
dificuldades em relacionar a mudança do comportamento gráfico às fases do movimento que haviam descrito anteriormente, com a ajuda do professor, mas a negociação de significados fica evidente. Esse é um exercício que requer certo grau de abstração e, talvez por isto, os alunos que não interagiram verbalmente pareciam muito atentos.

O compartilhar de significados, resultado da negociação dos mesmos, deve envolver, segundo Moreira (2000), permanente troca de perguntas ao invés de respostas, pois o ensino "[...] centrado na interação entre professor e aluno enfatizando o intercâmbio de perguntas tende a ser crítico e suscitar a aprendizagem significativa crítica" (MOREIRA, 2000, p. 6). Visto que o número de situações que possam efetivamente caracterizar negociações de significados foi pequeno em nosso estudo, e, ainda, tendo em vista a importância da interação dialógica para a aprendizagem, identificamos que a maioria dos alunos não conseguiu ou não quis se posicionar diante do novo conhecimento.

É certo que fatores diversos, como a cultura escolar que ainda valoriza o professor como detentor de respostas corretas e o aluno como reprodutor das mesmas, aspectos de natureza motivacionais e contextuais, por exemplo, quando o conteúdo não faz sentido para o aluno, podem fomentar o desinteresse pelo conteúdo específico da disciplina. Não obstante, nos interessa ressaltar que apesar de o professor, frequentemente, tentar motivá-los e se preocupar com o potencial do material educativo, a intencionalidade para a aprendizagem significativa não pode ser dividida com ele. $\mathrm{O}$ aluno é o responsável pela própria aprendizagem.

Respeitando o caráter pessoal da aprendizagem e a complexidade do nosso objeto de análise, buscamos outros indicadores que pudessem nos ajudar a esclarecer que intenções orientavam as falas e ações dos alunos no cotidiano da disciplina. Desse modo, por meio de entrevista, todos gostaram mais dos Blocos II e III da disciplina porque lhes pareceram mais aplicáveis e interessantes. No mesmo sentido, dez alunos gostaram menos de estudar os conceitos no Bloco I porque, segundo suas falas, "tinha que decorar", "era chato" ou "confuso". O A6, por exemplo, ao declarar não ter gostado "dessa parte meio decoreba dos conceitos", enfatizou: "en acabei decorando?". Apenas dois alunos (A7 e A8) disseram ter gostado de todo o conteúdo, embora interagissem pouco com o professor.

Essas respostas sugerem que apesar da preocupação em decorar os conceitos, os alunos se identificaram mais com a segunda parte da disciplina pela possibilidade de utilização do conhecimento em situações "reais".

Para compreendermos os comportamentos dos alunos durante as aulas e nas atividades extraclasse, bem como a concepção de aprendizagem dos mesmos, também contemplamos, na entrevista realizada, perguntas sobre seus hábitos de estudos desde o Ensino Médio até aquele momento. Enquanto cursavam o Ensino Médio, nove alunos estudavam somente às vésperas das provas (A1, A2, A3, A4, A6, A8, A11, A12 e A13), dois estudavam "mais ou menos, dependendo da matéria" (A7 e A9), e os outros dois diariamente (A5 e A10), sendo que um destes porque era obrigado pela mãe. Ou seja, tomando como base essas respostas, este grupo de alunos, sem perceber a importância do conhecimento para eles e o caráter processual e intencional da aprendizagem, antes de relacionar as novas ideias de forma substantiva e não arbitrária com seus conhecimentos prévios, buscou a memorização.

Quando pedimos que comparassem o tempo de estudo no curso superior e no nível anterior, nove alunos disseram "mais", um respondeu "igual" (A11), e três que estudavam, "menos" (A4, A5 e A8). Em relação à frequência com que estudavam o conteúdo da disciplina 
Biomecânica, A13 alegou estudar quase diariamente; A3, A6, A8, A10 e A12 disseram revisar o conteúdo discutido nas aulas em torno de uma vez por semana, e os outros sete alunos (A1, A2, A4, A5, A7, A9 e A11), somente estudavam às vésperas das provas. Um desses chegou a fazer uma espécie de "desabafo" dizendo: "Tô de saco cheio de estudar!".

Diante dos hábitos de estudo assumidos por esses estudantes, parece que a maioria pouco se comprometeu com a disciplina, e, o que nos parece mais grave, a maioria deles indica, mesmo que implicitamente, acreditar que estudar na véspera da prova é condição suficiente para aprenderem. Seguindo a mesma lógica, dois alunos nos disseram que estudaram durante a greve (A12 e A13), quatro, que muito pouco (A3, A7 e A10) e sete alunos não estudaram o conteúdo da disciplina neste período.

Em síntese, os hábitos de estudo da maioria dos alunos, construídos ao longo do processo de escolarização, apresentaram pequena, quando nenhuma, modificação na graduação. Essencialmente centrados no estudo eventual, motivado por provas, indicam que concebem aprendizagem como memorização, e não, como seria desejado, como um processo pessoal de relação (substantiva e não arbitrária) entre o novo conhecimento com o que já sabem.

A preocupação com a memorização por parte dos alunos, apesar do empenho do professor em ajudá-los a aprender significativamente, inclusive orientando-os sobre como estudar, era recorrente. Em várias ocasiões, inclusive em conversas entre a pesquisadora e alguns alunos pelos corredores, ficava clara a preocupação dos mesmos com a reprodução literal das definições dos conceitos, ou seja, na percepção deles, deveriam memorizar os conceitos com as mesmas palavras com as quais foram apresentados pelo professor ou pelo livro. $\mathrm{Na}$ aula 15, por exemplo, A13 relatou ter dificuldades para explicar os conceitos corretamente e que, por isto, acreditava que eles devessem ser memorizados. Para ele, a memorização garantiria o acerto que, por sua vez, seria um indicador de aprendizagem bem-sucedida. O professor, aproveitando a oportunidade para ajudar os alunos a se perceberem como responsáveis pela própria aprendizagem, reitera uma de suas constantes falas: "[...] por isso é importante estudar em casa e discutir em sala [...]", e acrescenta que "[...] há duas formas de se fazer um curso superior: reproduzir o que tem sido feito no ensino básico, ou procurar mudar [...]". Em seguida, complementa explicando a função do livro e a importância de se confeccionarem as respostas com as próprias palavras, esclarecendo que o teste referente ao Bloco I seria voltado para a avaliação da compreensão dos conceitos, o que não significava ter de repetir o livro literalmente.

Diante do exposto, é possível perceber que alunos e professor interagiam com diferentes concepções de aprendizagem. Os primeiros, habituados a "estudar para a prova" ou "para atender as demandas de seus professores", priorizavam a memorização. O professor, por sua vez, além de fomentar a participação nas aulas, também recorria a falas explícitas sobre como os alunos deveriam estudar, interagir com o conhecimento. Tal fato dificultou a aquisição de novos significados, a aprendizagem significativa, por parte dos alunos, pois como ressalta $\mathrm{Au}$ subel $(2003$, p. 83$)$ " [...] independentemente da quantidade de significado potencial inerente a uma determinada passagem de discurso relacionado, o material continua a ser apreendido por memorização, desde que o mecanismo do aprendiz seja assimilá-lo de modo literal".

Por outro lado, vale lembrar que a possibilidade de esses alunos abandonarem a concepção de aprendizagem que possuíam e passarem a utilizar a nova ideia apresentada, mais coerente com a aprendizagem significativa, dependeria que a incoerência explicativa e funcional desta ideia fosse por eles percebida. Tal condição demandaria, além do discurso do docen- 
te, que as atividades propostas, inclusive as avaliações, se caracterizassem como situações novas para os alunos, e, assim, sem condições de serem resolvidas com a reprodução literal do discurso do professor e/ou livro texto.

A natureza dos testes aplicados, por problema de espaço, não será abordada neste texto. Pode-se antecipar, entretanto, que as questões propostas, nas aulas e nas avaliações, buscavam a relação dos temas estudados com a prática profissional na área, ainda que nem sempre fossem percebidas e/ou assumidas como "problema" por parte dos alunos.

Considerando os indicadores apresentados, decidimos analisar, especificamente, as ações dos alunos A13 e A12, visto que o primeiro, apesar da clara preocupação em "decorar" os conceitos, foi o que mais interagiu com o professor (Gráfico 1). Era persistente e, caso não conseguisse captar os significados ou tivesse dúvidas sobre a correspondência entre o que havia captado e o que o professor havia apresentado, tentava esclarecê-las nas aulas ou após o término delas. Por vezes, levava exemplos diferentes dos apresentados pelo professor, na tentativa de utilizar os conceitos imediatamente ou anteriormente discutidos, a fim de verificá-los com o docente.

O aluno A12, por sua vez, apresentou uma participação mais tímida em sala de aula, mas acompanhava algumas das atividades realizadas no Laboratório de Biomecânica, embora sem muita regularidade. De acordo com as nossas observações, esse aluno, apesar de buscar esclarecer algumas dúvidas em aula, parecia mais preocupado com sua aprovação na disciplina do que com sua própria aprendizagem. Todavia, a avaliação do professor, manifestada na entrevista, contrariamente às nossas percepções, considerava que, nessa turma, apenas A13 e A12 efetivamente apresentaram disposição para a aprendizagem significativa. Explicou sua percepção contando que "[...] A12 sempre procurava traz̧er, fora das aulas, situaçoes que não eram as que nós discutiamos em sala de aula, para ver se ele tinha, realmente, entendido o conceito aplicado naquilo ali. E o A13 também, mas A12 era mais freqüente [...]”. Notamos que esse aluno não se expunha muito durante as aulas, mas, pelo relato do professor, grande parte de suas dúvidas era levada diretamente a ele em horários extraclasse. Quando perguntamos ao professor se os alunos the procuraram em outros horários, que não os das aulas, para pedir exercícios extras, o mesmo reiterou que somente A12 e A13 o fizeram.

Diante do exposto, podemos pressupor que, esses dois alunos - A13 e A12 - apresentaram, explicitamente, intenção para a aprendizagem significativa, inclusive pelo fato de tentarem empregar os conceitos discutidos durante as aulas em novas situações, buscando exemplos diferentes dos utilizados pelo professor. Apesar disso, quando o docente corrigia os exercícios em aula, sobretudo no Bloco I, os referidos alunos, assim como a maioria da turma, liam as respostas do caderno e pareciam reproduzir explicações dadas pelo livro. Por exemplo, durante a aula 13, A12 que, ao emitir justificativa idêntica à encontrada na página 327 de Hall (2000) para a questão "Conceitue centro de gravidade", apresentada em um dos exercícios, explicou que "[...] é o ponto ao redor do qual o peso e a massa do corpo estão equilibrados igualmente em todas as direçôes". Ou seja, mesmo os alunos que, aparentemente, empenhavam mais esforços em captar significados, como o caso de A13 e A12, apresentavam clara preocupação em aprender os conceitos de forma literal, tendendo à memorização.

Resumindo, A12 e A13 alegaram estudar frequentemente o conteúdo discutido na disciplina, estudaram no período de greve e procuraram o professor em horários extraclasse para esclarecer dúvidas e/ou pedir que lhes passasse tarefas extras, porém, paralelamente, 
também apresentavam clara preocupação com a memorização do conteúdo. Além disso, seus hábitos de estudo, assim como da maioria dos seus colegas, construídos ao longo do processo de escolarização, que comumente valoriza a memorização de conceitos, pouco se modificaram a ponto de que eles decidissem somente pela aprendizagem significativa. Entretanto, diante das evidências apontadas, pareceu-nos que os dois alunos (A13 e 12) ora tinham intencionalidade para a aprendizagem por memorização ora para a significativa.

\section{Considerações finais}

Assumindo que a intencionalidade/disposição para aprender significativamente é condição para a ocorrência da aprendizagem significativa (AUSUBEL; NOVAK; HANESIAN, 1980), buscamos identificar as ações dos alunos ao longo da disciplina Biomecânica, particularmente os aspectos cognitivos, atitudinais e afetivos que, positiva ou negativamente, interferiram no processo da aprendizagem dos mesmos. Sem desconsiderar o caráter complexo e subjetivo dessa proposta, nos baseamos em indicadores como: (a) a participação nas aulas, (b) a natureza das interações verbais entre professor e alunos, (c) as situações de interação que se caracterizaram como negociação de significados, (d) os hábitos de estudo, (e) o contato com o professor para esclarecer dúvidas em horários extraclasse, (f) pedido de tarefas extras às solicitadas pelo professor, e por último, (g) a avaliação do professor sobre as atitudes dos alunos no decorrer da disciplina.

De acordo com os dados, a correlação estatística entre o número de participações verbais (perguntas, comentários etc.) durante as aulas e o aproveitamento dos alunos é muito fraca, apontando que, isoladamente, este não é um indicador preciso para se atribuir intencionalidade para a aprendizagem significativa.

Entretanto, quando cruzado com outros aspectos, torna-se muito útil, especialmente quando se considera a natureza das situações de interação que integram o processo educativo. Identificamos que mais da metade das manifestações verbais dos alunos se limitaram a responder perguntas postas pelo professor. Situações de interação verbal, entre professor, material educativo e aluno, caracterizadas como episódios de negociação de significados, foram consideradas um indicador sobre a intencionalidade do aluno para aprender, ainda que esta intencionalidade nem sempre estivesse voltada para a aprendizagem significativa, como seria ideal. Contudo, no conjunto de aulas analisado encontramos poucas situações que poderíamos considerar negociações de significados na perspectiva de Gowin (1981).

As atitudes e os hábitos de estudo dos alunos influenciam a forma como eles interagem com o conhecimento e, portanto, o tipo de aprendizagem que, intencionalmente, buscam. No caso particular dessa turma, a maioria segue estudando às vésperas das provas, fato que indica intencionalidade para a aprendizagem mecânica e, em consequência, uma concepção de aprendizagem pouco coerente com a significativa. Além disso, apenas dois dos treze alunos apresentaram intencionalidade para aprender significativamente segundo o docente, pois também o procuraram em horário extraclasse para tirar dúvidas e pedir exercícios extras.

Levando-se em conta esses indicadores e o continuum aprendizagem mecânica-significativa explicado pela Teoria da Aprendizagem Significativa, é possível apontarmos que dois dos 13 alunos interagiam com o novo conhecimento por vezes de forma mecânica e, por 
Belmont, R. S.; Lemos, E. S.

outras, tentando fazer relações substantivas e não literais, ou seja, esses alunos transitavam entre ambas as aprendizagens, ora buscando a memorização e ora a aprendizagem significativa. Os demais estudantes não apresentaram tais evidências durante o processo de ensino e de aprendizagem da Biomecânica.

Ressaltamos, por último, que o presente estudo não pretendeu esgotar o tema, mas anunciar a importância de se considerar, além dos conhecimentos prévios do aluno sobre o conteúdo a ser ensinado, a concepção de aprendizagem que orienta as ações do mesmo no contexto educativo. Embora ocupadas com um caso particular, acreditamos que o resultado desta investigação pouco difere do que comumente encontramos nos contextos educativos. Ou seja, o significado de aprendizagem, embora não seja um tema específico da Educação Básica e nem de boa parte dos cursos da Educação Superior, é aprendido - e implicitamente ensinado - no processo de escolarização.

\section{Referências}

AMADIO, A. C.; SERRÃO, J. C. Biomecânica: trajetória e consolidação de uma disciplina acadêmica. Revista Paulista de Educação Física, São Paulo, v. 18, p. 45-54, ago. 2004. (Número especial).

AUSUBEL, D. P. Aquisição e retenção de conhecimentos: uma perspectiva cognitiva. Lisboa: Plátano, 2003.

AUSUBEL, D. P.; NOVAK, J. D.; HANESIAN, H. Psicologia educacional. Rio de Janeiro: Interamericana, 1980.

BARDIN, L. Análise de conteúdo. 4. ed. Lisboa: Edições 70, 2009.

BATISTA, L. A. Biomecânica em educação física escolar. Perspectivas em Educação Física Escolar, Niterói, v. 2, n. 1, p. 36-49, 2001 a.

. Sports biomechanics - readings and research biomechanics and scientific knowledge applicability. In: FARO, A. (Org.). A multidisciplinary approach to human movement. Coimbra: Imprensa de Coimbra, 2001b. p. 225-243.

BRASIL. Conselho Nacional de Educação. Conselho Pleno. Parecer n. 28, de 02 de outubro de 2001. Dá nova redação ao parecer CNE/CP 21/2001, que estabelece a duração e a carga horária dos cursos de Formação de Professores da Educação Básica, em nível superior, curso de licenciatura, de graduação plena. Diário Oficial da União, Brasília, 18 jan. 2002. Seção 1. p. 31. Disponível em: < http://portal.mec.gov.br/cne/arquivos/pdf/ 028.pdf>. Acesso em: 2 jan. 2009.

ENOKA, R. M. Bases neuromecânicas da cinesiologia. São Paulo: Manole, 2000.

GOWIN, D. B. Educating. New York: Cornell University Press, 1981.

GRAPHPAD PRISM. Version 5.00 for Windows, GraphPad Software. San Diego California, USA, 2007. 
A intencionalidade para a aprendizagem significativa ...

HALL, S. Biomecânica básica. 3. ed. Rio de Janeiro: Guanabara Koogan, 2000.

LEMOS, E. S. A aprendizagem significativa: estratégias facilitadoras e avaliação. Série Estudos: Revista do Mestrado em Educação da UCDB, Campo Grande, n. 21, p. 53-66, jun. 2006.

LÜDKE, M.; ANDRÉ, M. E. D. A. Pesquisa em educação: abordagens qualitativas. São Paulo: EPU, 1986.

MOREIRA, M. A. Aprendizagem significativa. Brasília: UnB, 1999.

. Aprendizagem significativa subversiva. In: ENCONTRO INTERNACIONAL SOBRE APRENDIZAGEM SIGNIFICATIVA, 3., 2000, Peniche. Anais... Peniche: Universidade de Alberta, 2000. p. 33-45.

NOVAK, J. D. Aprender, criar e utilizar o conhecimento: mapas conceituais como ferramentas de facilitação nas escolas e empresas. Lisboa: Plátano, 2000.

SANDERS, R.; SANDERS, L. Improving dissemination and application of sport science to physical educators. Motriz, Rio Claro, v. 7, n. 1, p. s1-s5, jan./ jun. 2001. (Suplemento).

Artigo recebido em 03/02/2011. Aceito em 18/10/2011. 